\title{
Understanding the overlap between $O C D$ and trauma: development of the OCD trauma timeline interview (OTTI) for clinical settings
}

\author{
Lauren P. Wadsworth ${ }^{1}$ (D) $\cdot$ Nathaniel Van Kirk ${ }^{2} \cdot$ Madeline August $^{1} \cdot$ J. MacLaren Kelly ${ }^{1} \cdot$ Felicia Jackson ${ }^{1}$. \\ Jennifer Nelson ${ }^{1} \cdot$ Rose Luehrs $^{2}$
}

Accepted: 12 July 2021 / Published online: 23 July 2021

(C) The Author(s), under exclusive licence to Springer Science+Business Media, LLC, part of Springer Nature 2021

OCD is estimated to impact $1.2 \%$ of the United States population annually, and $2.3 \%$ of individuals in the United States at some point in their lifetime (Ruscio et al., 2010). However, as noted by Badour et al. (2012), the prevalence rate of OCD is considerably higher among those with Post Traumatic Stress Disorder (PTSD). In the National Comorbidity Survey Replication, those with a current diagnosis of PTSD were 3.62 times more likely to have OCD, whereas those with a current OCD diagnosis were not at greater risk of having PTSD leading some to speculate whether symptoms of PTSD serve as precipitating factors of OCD (Brown et al., 2001). Estimates of comorbidity vary based on the principal diagnosis considered and on whether considering current or lifetime (current and past) diagnoses. Reports range from 19\% (lifetime comorbid PTSD and OCD; Ruscio et al., 2010 ) to $31 \%$ (current principal PTSD and lifetime diagnosis of OCD; Brown et al., 2001), 23\% with current principal PTSD with co-occurring OCD (Brown et al., 2001). Those diagnosed with OCD often (54\%) endorse experiencing one or more traumatic life events (Cromer et al., 2007). Indeed, according to Dykshoorn (2014), between 30 to $82 \%$ of those diagnosed with OCD have a trauma history.

Experiences of traumatic life events have been documented in the literature as associated with greater Yale-Brown Obsessive Compulsive Scale severity scores overall in a sample of adults seeking treatment for OCD (Cromer et al., 2007).

OCD Trauma Timeline Interview (OTTI)

Lauren P. Wadsworth, PhD; Nathaniel Van Kirk, PhD; Madeline August, $\mathrm{PhD}$

Contact for questions/use: drwadsworth@gviproc.org

Lauren P. Wadsworth

Lauren.p.wadsworth@gmail.com

1 Genesee Valley Psychology, 200 White Spruce Blvd, Suite 220, Rochester, NY 14623, USA

2 McLean Hospital, 115 Mill Street, Belmont, MA 02478, USA
While recent findings by Ojserkis et al. (2017) suggest those with a primary diagnosis of OCD tend to have more severe and impairing obsessive-compulsive (OC) symptoms longitudinally if they have a lifetime comorbid PTSD diagnosis, evaluation of its impact on treatment outcome and long term recovery is still in the early phases. While early case reports have documented the difficulties in treating comorbid OCD and PTSD (e.g., Gershuny et al., 2003; Riggs, 2000), these findings have not been universal (e.g., Shavitt et al., 2010). Notably, Gershuny et al. (2008) found $82 \%$ of those with primary OCD who were identified as "treatment resistant" reported a history of trauma. Further, the presence of comorbid PTSD was found to impede OCD treatment response in intensive/residential settings for those with treatment refractory OCD (Gershuny et al., 2002). Taken together, these findings suggest significant and concerning treatment barriers may exist when treating co-occurring OCD and PTSD.

Understanding the temporal sequence of symptom onset might be one key aspect of understanding the overlap of OCD and PTSD. A systematic investigation of the presence of OCD symptoms in adults with combat-related PTSD found that more than half of the sample (59\%) developed symptoms of OCD following traumatic exposure (Nacasch et al., 2011). Evaluation of this overlap using the National Comorbidity Survey Replication (Ruscio et al., 2010) found that $39.4 \%$ of individuals reported OCD symptoms preceding development of PTSD. In $39.9 \%$ of cases, OCD developed a year or more after PTSD. Interestingly, the remaining cases $(20.7 \%)$ reported onset of both symptom sets within the same year. A subsequent study found that patients who develop OCD following the onset of PTSD symptoms (or who develop OCD \& PTSD at the same time) typically have a later age of OCD onset, along with higher rates of OC symptoms, as well as a more severe clinical presentation than patients who developed OCD prior to PTSD onset (Fontenelle et al., 2012). This increased level of severity is concerning, as it is tethered to considerably greater suicidality and variability in other 
comorbid disorders, including anxiety, mood, impulse control, and somatoform disorders (Fontenelle et al., 2012).

Another important aspect of the OCD/PTSD overlap highlighted by the treatment case series literature is the potential for a functional connection between OCD and PTSD symptom sets. More specifically, OCD has been observed to function as a (maladaptive) coping mechanism in some instances, reducing contact with trauma-related thoughts/images (e.g., Gershuny et al., 2003; Van Kirk et al., 2018). Similar phenomena have been described with other comorbidities such as OCD and borderline personality disorder, where a functional connection between symptom sets results in comorbid symptoms maintaining each other (see Grayson, 2010 for a description of merged $O C D$ ). OCD/PTSD comorbidity may occur when OCD rituals not only neutralize obsessional fears, but also help avoid intrusive traumarelated recollections or when the OCD feared consequences overlap with a past traumatic event. For example, an individual who developed PTSD and OCD following a traumatic car accident might drive 42 (a "lucky" number) miles per hour on the highway, both neutralizing fears of being unlucky again (OCD), which might elicit feeling a sense of control (OCD/PTSD), and allow them to avoid triggering memories of the car accident (PTSD). When this dynamic comorbidity is observed between OCD and PTSD symptoms, case studies have suggested decreases in OCD symptoms during treatment may result in a spike in PTSD symptoms and vice versa (e.g., Gershuny et al., 2003; Van Kirk et al., 2018).

An additional aspect underlying the OCD/PTSD comorbidity is the experience of mental contamination, previously referred to in the literature as mental pollution (Rachman, 1994). Mental contamination appears often in both the trauma and OCD literatures indicating it may be a link between trauma-related disorders and OCD. Decades ago, Rachman (1994) explained the concept of mental pollution, suggesting individuals experience an internal sense of uncleanliness following direct or indirect contact with something that is considered "polluted." In more recent literature, this term has been refined and is now often referred to as mental contamination, which furthers the earlier definition by suggesting the internal unclean sensation is brought on by human sources of violation, abuse, or adversity (Rachman et al., 2012). Due to the suspicion that mental contamination is human caused, and not thought to be caused by unclean inanimate objects, researchers have begun investigating the presence of mental contamination in both OCD and PTSD following exposure to adverse experiences. For example, one experiment with female college students sought to measure mental contamination by introducing imaginary scenarios of unwanted sexual experiences and then asking the female students to rate feelings of mental pollution. Findings suggested that even in the case of imagined unwanted sexual contact, participants reported significantly higher rates of feeling unclean, dirty on the outside, and dirty on the inside relative to participants in the comparison condition who were given an imaginary consensual situation (Fairbrother et al., 2005, replicated by Elliott \& Radomsky, 2013 and replicated in males by Rachman et al., 2012).Taken together, these findings indicate that mental contamination may be an underlying factor in cases of comorbid PTSD and OCD following traumaparticularly if the traumatic event was human caused, as was the case in these experiments. Moving forward, research should consider assessing and targeting interventions toward mental contamination in treatment seeking individuals presenting with OCD and PTSD.

Understanding the overlap and differentiation of present OCD and PTSD symptoms can improve treatment. One gold standard treatment for PTSD is Cognitive Processing Therapy (CPT) which involves the cognitive restructuring of negative automatic thoughts (Blankenship, 2017). While cognitive restructuring can be extremely helpful in treating trauma, it can have deleterious effects on OCD symptoms (Pinciotti et al., 2020) if the cognitive strategies are inappropriately applied to obsessions. Simultaneously, Exposure and Response Prevention (ERP) is the gold standard for OCD, and involves exposure to triggering stimuli. Exposing people to traumatic triggers before teaching appropriate trauma coping skills can severely interfere with OCD treatment (Pinciotti et al., 2020), perhaps making treatment feel unsafe. Similarly, while cognitive approaches, such as Cognitive Processing Therapy (CPT; Resick et al., 2016) for PTSD and cognitive therapy for OCD (e.g., Wilhelm \& Steketee, 2006) have been found effective, it is important to note there are important distinctions between which cognitive therapy skills are utilized between the two disorders. Thus, it is imperative that clinicians and clients have a common understanding of what symptoms are attributed to OCD, PTSD, and which overlap, to properly inform treatment implementation.

The current paper presents a novel clinical tool designed by the authors to help clinicians better understand the onset and presentation of OCD and PTSD symptoms. Further, administration can help clinicians and patients understand and address any overlap of OCD and PTSD symptoms. We theorize treatment and research implications and future directions.

\section{The OCD Trauma Timeline Interview (OTTI)}

The OCD Trauma Timeline Interview (OTTI; Appendix 1) is a clinical tool developed by the authors to help clinicians and clients better understand OCD and PTSD symptom origins, overlaps, and identify potential functional connectivity. Understanding symptom origin, overlap, and functional connectivity can then inform treatment order and implementation strategies. Administering the OTTI may also help clients feel 
more understood as they navigate exploring an often complex symptom overlap with their clinician.

\section{Diagnostic Assessment}

The OTTI should only be performed if the client and clinician agree that OCD and PTSD are both present. OCD and PTSD can be assessed using the validated diagnostic assessment preferred by the clinician. Future research on the OTTI will explore expanding its use to all trauma-exposed individuals.

Well validated assessments that offer both OCD and PTSD assessments include the MINI International Neuropsychiatric Interview (MINI; Sheehan et al., 1998), SCID-5-Clinical Trials Version (SCID-5-CT, First et al., 2015), and the Diagnostic Interview for Anxiety, Mood, and OCD and Related Neuropsychiatric Disorders (DIAMOND; Tolin et al., 2018). Clinicians can assess OCD in more detail using the Yale-Brown Obsessive-Compulsive Scale (Y-BOCS; Goodman, 1989a, Goodman, 1989b), and the Dimensional Obsessive-Compulsive Scale (DOCS; Abramowitz et al., 2010). The YBOCS provides a severity rating (0-40) for OCD symptoms, while the checklist helps clinicians assess the particular domains in which pt. is experiencing obsessions and is engaging in rituals. Clinicians can assess PTSD symptoms using the Post Traumatic Stress Disorder Checklist for DSM-5, (PCL-5; Blevins et al., 2015). The PCL-5 is a 20-item self-report measure that can be utilized to screen for PTSD and/or monitor symptoms across treatment, following diagnosis with a more comprehensive assessment tool (noted above).

\section{Preparing for 0TTI Administration}

Anecdotally, we have found the OTTI to be most beneficial when utilized with clients that have received psychoeducation for both OCD and PTSD. Following diagnostic assessment and any additional symptom measures, clinicians can provide psychoeducation on the symptoms of OCD and PTSD. Special attention to the overlaps, such as the urge to reduce anxiety/increase perception of safety, and the reinforcing factor of avoidance/rituals may be especially helpful in preparing for the OTTI. The OTTI includes an optional script for brief psychoeducation on OCD and PTSD. Therapists should provide psychoeducation in line with their therapeutic orientation and treatment modality.

\section{OTTI Administration}

The interview can be performed by the primary clinician, another clinician, or a trained research assistant. In cases of severe PTSD or trust difficulties, we recommend the interview be completed by the client's clinician. The interview typically takes $30-60 \mathrm{~min}$ to administer. Extra time should be allotted within or across interview sessions to address any traumatic memories or dysregulation triggered by the interview. In these cases we recommend engaging the client in grounding skills and refocusing on current symptoms as opposed to processing past events.

OTTI Example To display how we would administer the OTTI and fill out Table 1, we will use a fictitious case. Imagine "Simon", a 40 year old cisgender Black male presenting to treatment inquiring about an increase in symptoms in the onset of COVID-19 pandemic. Simon reports excessive cleaning, checking CDC guidelines and statistics, heightened anxiety and avoiding any exposure to the world outside of his home. He reports that the above symptoms adversely impacted his family system, as his worry leads to excessive monitoring of his partner and children including preventing them from leaving the home, promoting excessive hygiene behaviors (ex: handwashing, wiping groceries down, etc.) and preoccupation with their physical health.

Perhaps Simon discloses a traumatic experience of the death of his father five years prior in an automobile accident. Simon reports typical PTSD symptoms related to this experience including intrusive memories, avoidance of stimuli related to father, avoidance of emotions related to father's death, guilt, difficulty concentrating, difficulty sleeping and trauma cognitions. His trauma related cognitions may cluster primarily in thoughts that he should have done more to prevent his father's accident. He might harbor significant responsibility for his father's death leading to feelings of guilt and shame.

\section{Timing of Onset}

With regard to symptom onset, imagine Simon reports that he had always experienced subthreshold anxiety, never amounting to significant impact on his functioning. In the context of his father's passing he noticed an increase in baseline anxious symptoms in conjunction with PTSD symptoms noted above. It is easy to imagine that at the onset of the COVID-19 pandemic Simon might notice intrusive thoughts, excessive cleanliness and a preoccupation with the physical safety of his family members. This example emphasizes PTSD symptoms as occurring initially following a traumatic experience, with OCD symptoms following five years later in the context of a concrete trigger-the COVID-19 pandemic.

\section{Potential Overlap of OCD/PTSD}

Exploring the Simon example, a potential link between Simon's OCD and PTSD symptoms could be; the prevention of contamination from COVID-19 and cognitions related to responsibility and blame in the context of his father's death. The fear of contamination of self or family members triggered trauma-related feelings of responsibility and shame, leading the client to engage in rituals to avoid the painful feelings. Perhaps Simon names a trauma cognition "I am completely responsible for my father's 
Table 1 OCT Trauma Timeline Interview (OTTI) symptom chart

\begin{tabular}{|c|c|c|c|}
\hline $\begin{array}{l}\text { Obsessions/Thoughts } \\
\text { that overlap between } \\
\text { PTSD/OCD }\end{array}$ & $\begin{array}{l}\text { Rituals or Avoidance } \\
\text { Behavior }\end{array}$ & $\begin{array}{l}\text { Which more accurately } \\
\text { describes the feeling } \\
\text { you achieve by } \\
\text { completing the ritual? } \\
\text { a. A greater sense of safety } \\
\text { b. A greater sense of } \\
\text { certainty around future } \\
\text { outcomes }\end{array}$ & $\begin{array}{l}\text { If you resist the [Identified } \\
\text { Ritual/Behavior] do you } \\
\text { experience intrusive } \\
\text { thoughts or images of: } \\
\text { a. Past stressful events } \\
\text { b. Potential future scenarios } \\
\text { (e.g., "what if" scenarios)? }\end{array}$ \\
\hline $\begin{array}{l}\text { If I don't wipe the car } \\
\text { door handle down the } \\
\text { kids will get } \\
\text { COVID-19 and die }\end{array}$ & $\begin{array}{l}\text {-Excessively wipe } \\
\text { surfaces } \\
\text {-Wash own hands } \\
\text { multiple times } \\
\text { - Monitor kids multiple } \\
\text { hand washing }\end{array}$ & $\begin{array}{l}\text { B. At least my kids are } \\
\text { safe now }\end{array}$ & $\begin{array}{l}\text { B. What if the kids get sick } \\
\text { and die }\end{array}$ \\
\hline $\begin{array}{l}\text { I am responsible for } \\
\text { keeping everybody } \\
\text { safe }\end{array}$ & $\begin{array}{l}\text { Avoids } \\
\text { memories/pictures/- } \\
\text { stories of/about father }\end{array}$ & $\begin{array}{l}\text { A. I don't have to relive } \\
\text { painful memories }\end{array}$ & A. Images of father dying \\
\hline
\end{tabular}

Note. Full OTTI can be found in Appendix 1 death," which leads to an examination of the way this is impacting his current OCD symptoms.

The theme of Simon "feeling completely responsible" for his father's death likely would cause the future-oriented obsessive thoughts related to the safety of those around him. For example, thoughts such as "If I don't wash my hands 5 times, I will contract COVID and pass it to my family member," could emerge. A theme of responsibility for the safety of others might not only amplified the Simon's compulsive urge to take control of his environment in response to obsessional fears, but also prevent the re-occurrence of the trauma-related feared consequence, specifically the death of a loved one (e.g. "I can't let that happen again" and "I can't be responsible for the loss of another family member"). In this way, thoughts regarding responsibility, blame and control could serve as both solidified and impactful trauma-related cognitions and mechanisms for engaging with OCD-related thoughts and behaviors regarding contamination.

Perhaps Simon also reported that emotions arising in the context of obsessive thoughts related to COVID-19 contamination felt reminiscent of the day his father died, including visceral experiences of dread, sadness and anxiety. This would emphasize a potential primary motivator for coping through avoidance, as Simon could be constantly aiming to avoid sitting with his negative emotions.

Using this example, Simon's preoccupation with his family member's safety and current OCD-related behaviors can be conceptualized as 1) an OCD process in that rituals aim to prevent the occurrence of the feared consequence- anxiety related to feeling contaminated and potential harm coming to a family member and 2) a trauma process in that the behaviors are a way to avoid reexperiencing- including memories and the associated agonizing pain and guilt that he felt prior when he lost his father. We have outlined the above process using the Simon example in Table 1.

\section{Treatment Implications}

The OTTI administration and table can help clinicians and clients determine the best approach for treatment. Some clients benefit from focusing on one disorder first (e.g. OCD or PTSD) before treating the other. Others benefit most from an integrated/concurrent approach, completing the psychoeducation phase for both OCD and PTSD, followed by in session and between session work targeting both simultaneously. Order effects should be decided on a case by case basis. Future research is needed to determine best practices for co-occurring OCD and PTSD. Specifically, patients would benefit from learning how to distinguish between traumarelated thoughts (often past-focused) and intrusive thoughts (often future-focused).

\section{Trauma Specific Treatment}

Cognitive Processing Therapy (CPT) helps clients identify trauma-related core beliefs, or "stuck points," and engage in cognitive restructuring to reshape these beliefs (Resick et al., 2016). CPT can help clients challenge stuck points related to their traumatic experiences. Socratic questioning, context building and emotional processing of thoughts such as, "I am responsible for keeping everybody safe" or "It is my fault that my father died" can be utilized to challenge these stuck points with the aim of reducing guilt and self-blame, and can ultimately result in alternative and reality based thoughts related to traumatic events. Once the client is practiced at challenging trauma-related stuck points, they can apply this skill when they notice stuck points arising in the future or in the context of their OCD treatment.

Identifying and challenging trauma-related stuck points can allow for increased readiness to engage in the ERPs necessary to address OCD-related symptoms. For example, Simon's rigidly held belief that he was responsible for the death of his 
father served as a barrier to completing ERPs which require engaging in behaviors that trigger fears of being responsible for others' safety. Thus initial targeting of trauma-related beliefs could improve willingness and efficacy of subsequent treatment of OCD symptoms by giving the client the tools to effectively manage the emergence of trauma-related stuck points that may function as treatment interfering behaviors.

Alternatively, a Prolonged Exposure (PE) framework could be utilized to help the client practice bringing trauma memories to mind and experiencing corresponding emotions (Foa et al., 2019). Over time, PE can help clients process emotions related to traumatic experiences and learn that trauma-related memories and cues are not inherently dangerous. The PE framework also emphasizes exposure to feared stimuli in the client's environment. In this way, a PE framework can overlay ERP treatment for OCD, as mechanisms of triggering emotions intentionally, sitting with them, and reducing avoidance, are key components across both treatments (Foa et al., 2019).

\section{OCD Specific Treatment}

Cognitive behavioral therapy (CBT) approaches for OCD have demonstrated robust empirical support, including in meta-analysis (Eddy et al., 2004). The core component of CBT approaches, Exposure and Response Prevention (ERP) asks clients to approach situations, objects, or thoughts that are typically avoided because they trigger intrusive thoughts and distress (e.g. exposure). Importantly, these triggers must be approached while the client tolerates the experience of distress and uncertainty without engaging in compulsive, ritualized behaviors to reduce the distress (e.g. ritual prevention). Through repeated exposure and processes such as fear habituation and/or inhibitory learning, over time the client learns safety in situations previously perceived as dangerous or threatening. The client also learns that he can tolerate uncomfortable emotions (Foa et al., 2012; Craske et al., 2014).

Using the Simon example, exposures could involve contact with contaminants by touching door handles and other objects or surfaces that Simon perceives as unclean. Response prevention could involve Simon resisting the urge to excessively wash his hands, wipe off surfaces or monitor his children's hand washing.

Similarly, the Simon example illustrates potential overlap of inflated responsibility in the context of OCD and PTSD related cognitions (Salkovskis, 1985). In these contexts, clinicians may utilize cognitive interventions including behavioral experiments, practicing the delay tactic and/or cognitive strategies including responsibility pies and contracts to target intrusive thoughts related to responsibility and checking behaviors (Radomsky et al., 2010).

When there is an overlap between OCD and PTSD symptoms, clinicians must be mindful that ERPs may not only trigger OCD-related fears of future consequences but could also evoke trauma-related memories of the past. In such circumstances, it is important to be deliberate in the goals of the ERP and for both the client and the therapist to be mindful of the thoughts being targeted (Riggs, 2000) and plan for appropriate use of the trauma vs. OCD treatment strategies. As such, the OTTI is a particularly helpful tool to acknowledge and plan for exposures that are likely to trigger intrusive fears, traumatic memories or a combination of the two.

\section{Recommendations for Clinicians}

The OTTI may provide an initial framework/foundation for developing more standardized assessments of this OCD/ PTSD comorbidity and assisting with treatment formulation. Despite the high percentage of co-occurring OCD and PTSD, we have limited clinical resources specifically developed to navigate treatment for such cases and identify emergence treatment barriers. When both are present, OCD rituals and avoidance behaviors can be hard to differentiate from PTSD safety behaviors and avoidance. In addition, the comorbidity may present in a static (i.e. independent) or dynamic (i.e. interconnected) fashion (Rachman, 1991), potentially influencing symptom presentation and treatment response. In order to increase our understanding of these different presentations and to provide a framework for treatment planning, a more tailored framework for evaluating this comorbidity is needed (in both clinical and research domains).

Following Rachman's (1991) recommendations around determining comorbidity presentation and identifying potential functional connections between OCD/PTSD symptoms to inform treatment approach (Fletcher et al., 2020), this interview sought to provide a framework to evaluate these connections, individual perceptions of how OCD and PTSD symptoms may relate to one another, and how behavioral responses may be similar or distinct. The interview can also offer insight into barriers to engaging with ERP. We believe that the interview is best utilized after completion of initial psychoeducation around OCD and PTSD symptoms, so the client can work alongside the clinician to identify distinct OCD and PTSD symptoms, and the overlap. The interview findings can lead into an informed discussion of treatment order (e.g., trauma treatment followed by OCD treatment, the reverse, or engaging in both treatments in parallel). The findings can also help the therapist connect the client's experience to previous research on the order effects of OCD and PTSD development, and anticipate potential treatment barriers.

Each aspect of OCD and PTSD symptoms should be carefully explored. For example, it is key to carefully distinguish between PTSD related hypervigilance and safety behaviors and OCD rituals. In some cases, hypervigilance and safety behaviors (e.g., sitting with one's back to the restaurant wall, 
frequently scanning the room) are easy to distinguish from OCD rituals (e.g., adding ' 1 ' to any odd number encountered in the world to make it even). However, sometimes these behaviors can look strikingly similar (e.g., checking children's locations on their phones to assess for likelihood of contamination, asking children to wash thoroughly upon returning home). The OTTI can help explore these behaviors by assessing if these behaviors are aimed at gaining certainty versus achieving a feeling of safety and avoidance of reexperiencing symptoms, or if they function to achieve all three.

The OTTI could potentially be extended beyond clients with PTSD, to also include those with trauma exposure without PTSD. To date, we only utilized the OTTI with clients who met criteria for PTSD (excluding those with trauma exposure without PTSD). The definition of trauma in the context of conceptualization and diagnosis has been of consistent debate in the field of trauma focused treatment, ranging across a dimension from a specific, isolated traumatic experiences, often referred to as 'single incident trauma' to complex and frequently occurring trauma experiences, referred to as 'complex trauma' (Courtois, 2004; Herman, 1992). In the scope of the current interview, the choice was made to include the DSM-IV Criterion A definition of trauma and the Life Events Checklist (Gray et al., 2004) to cast a relatively wide net in assessing the impact of a variety of traumatic experiences. However, as the above assessments are typically utilized to assess single-incident trauma, future iterations of the interview may benefit from the inclusion of measures specifically aimed at assessment of chronic and long-lasting traumatic experiences, including complex or developmental trauma disorder (van der Kolk, 2005). Additionally, it will be important to understand the potential links between traumaexposure, in the absence of meeting full criteria for PTSD and development, co-occurrence or maintenance of OCD symptoms.

Our work should be considered in light of a few potential limitations. To date, we have only used the OTTI in clinical settings. The OTTI might not be helpful when clients are new to treatment, before completing OCD and PTSD psychoeducation (as they might not be able to differentiate between OCD and PTSD symptoms), or might have minimal insight into ritualistic and avoidance behaviors and associated thoughts and feelings. The OTTI could be counterproductive if clients are experiencing severe obsessions of "needing to know" or "saying just the right thing" as it may cause the OTTI to be burdensome and hard to navigate. However, clients with these experiences could likely be coached to give their "best answer" later in treatment, and the interview could potentially be used as an exposure.

Our work has a number of important future directions. First, we will pursue a pilot study to systematically collect and evaluate data from the OTTI, its psychometric properties, and its relationship to treatment outcome. Next, we will attempt to broaden the scope of the interview to include clients who are trauma exposed, who do not meet criteria for PTSD. Overall, the literature on the overlap between OCD and PTSD is still limited. The field would benefit from studies exploring symptom overlap, temporal precedence, functional connectedness of symptoms, as well as identifying specific factors that increase treatment resistance in co-occurring PTSD and OCD (e.g., is treatment resistance in residential settings due to symptom overlap, ineffective treatment of PTSD in these primarily OCD targeted settings, or both).

\section{Appendix 1}

\section{OCD Trauma Timeline Interview (OTTI)}

Lauren P. Wadsworth, PhD; Nathaniel Van Kirk, PhD; Madeline August, $\mathrm{PhD}$

Contact for questions/use: drwadsworth@gviproc.org

\section{Part A}

1. Today I will be asking you questions about your mental health symptoms, with a specific focus on your experience of OCD and traumatic experiences. [If in therapy] We will be recording today's interview so that your therapist can better understand the information that we discuss and so that we may refine this interview for future patient care. Some of the questions in this interview may bring up intense feelings or reactions. Please let me know at any time if you would like to pause or stop the interview.

a. (Optional Psychoeducation) "When learning to understand your OCD symptoms, it's important to have a good grasp of the core elements that make up OCD obsessions and compulsions. While the term "obsession" can be used in a variety of ways, we characterize obsessions as thoughts, images, or urges that are experienced as unwanted and intrusive, ultimately causing significant distress. Obsessions can cause a wide range of distressing emotions, including anxiety, disgust, incompleteness, guilt, and not just right experiences (NJRE).

In response to the distress caused by obsessions, individuals with OCD engage in compulsions/rituals in an attempt to prevent a feared consequence associated with the obsessions or neutralize the thought or associated distress. While compulsions can take nearly any form, there are certain characteristics that help us differentiate compulsions from functional behavior. First, compulsions are behaviors or thoughts/mental actions that are 
carried out in a repetitive and rigid manner. Second, they are excessive in nature. Most importantly, while compulsions may be effective in providing temporary relief from distress, they ultimately reinforce the OCD cycle and the obsessional thought as something to be feared.

While OCD symptoms are heterogenous, four major dimensions of OCD have been found: 1) contamination fears with washing style compulsions, 2) harm obsessions, 3) obsessions around sex, religion, and violence and mental compulsions, and 4) order, symmetry, and not just right experiences. Regardless of the type of symptoms, central to the OCD cycle is a fear of uncertainty. As a result compulsions are completed in an attempt to gain feelings of $100 \%$ certainty. However, it is important to understand that the experience of unwanted thoughts is a common human experience and the content of thoughts does not differ between those with OCD and those without. It's the interpretation of those thoughts as meaningful that results in distress.

When we talk about PTSD, we are referring to a group of symptoms that develop following experiencing a trauma. The DSM 5 defines a trauma as being directly exposed to, witnessing, or having learned about a traumatic experience happening to a family member or friend, or repeatedly exposed to details of events of an experience that involves actual or threatened death, serious injury, or sexual violence. Following exposure to a traumatic event, individuals with PTSD may experience a variety of symptoms that span re-experiencing/intrusion, avoidance, alterations to thoughts and general mood, and arousal symptoms.

Re-experiencing symptoms can take many forms, but typically include experiencing intrusive and distressing thoughts, images, or dreams associated with the traumatic experience. Additionally, an individual may experience increased feelings of distress (both psychological and physiological) to cues or reminders associated with the event. For some individuals they may even feel as if they are back in the situation again or like the event is occurring again.

As a result of the distress experienced following from these intrusive recollections, individuals with PTSD attempt to avoid cues that may remind them of these events or trigger associated distress. This can take the form of either attempts to avoid memories, thoughts, or feelings that have become associated with the event or memories of the event, or attempts to avoid any reminders of the event in their daily life (such as people or places, or certain topics and activities). The goal of this avoidance is to not experience the distressing thoughts or memories associated with the trauma - however, similar to in OCD, this avoidance serves to maintain the PTSD symptoms and distress in the long term.

Individuals with PTSD also experience more general changes to their mood and beliefs following experiencing a trauma. They may notice an increase in overall negative beliefs about the world or themselves that are persistent and become more extreme and generalized following the trauma or even distortions around their beliefs about why the trauma happened or their role in the event. For some individuals they may struggle to remember certain aspects of the trauma itself. These changes can also lead to a more generalized negative feeling throughout their day, feelings of detachment, reduced interest in activities that they previously enjoyed and even difficulty experiencing positive emotions such as happiness or love.

Finally, individuals with PTSD typically report significant changes in their feelings of arousal, reporting that they may feel on edge, irritable, or hypervigilant throughout their day. This may be observed as being easily startled or having difficulty concentrating or sleeping. In some cases, this may also result in self-destructive behavior. Overall, this may feel like pervasive feelings of being unsafe as one is always on the lookout for danger or reminders of past traumatic events.

Differentiating OCD and PTSD can be difficult. At first glance, the criteria share many overlapping features (i.e. intrusive and unwanted thoughts, repetitive behaviors aimed at reducing distress). To tease them apart, consider what the primary goal of your behavior is. If your primary goal is to escape reexperiencing symptoms or thoughts and memories tied to a specific traumatic event (including flashbacks), it is likely a PTSD symptom. If your goal is to reduce feelings of uncertainty or to prevent something bad from happening in the future (that is not tied explicitly to a past traumatic event) it is likely an OCD symptom.

You can also use the frequency of behaviors to distinguish symptoms. In OCD, compulsions/rituals are repeated and rigid in their implementation. They tend to increase over time in complexity and/ or the extent they have to be repeated (in order to achieve a sense of certainty). PTSD, on the other hand, involves behaviors that attempt to increase feelings of safety (vs. gain absolute certainty) and avoid aspects of past events. While the avoidance might increase over time (for example, avoiding more and more people/places/things) it isn't repeated in the way that rituals are (over and over in a short period of time) and has a less rigid focus on how the behavior/act is completed. 
This table (hand to patient) can be used as a guide to differentiate symptoms, but if you have questions, feel free to ask at any time. Do you have any questions before we begin?"

i. The below table can be used to enhance psychoeducation/ understanding of the differences between OCD and PTSD:

OCD

Thought Content Future focused.... what ifs?; span more domains

More rigid set of rules; focused on the "how;" growing complexity; Preventing trauma from reoccurring; Feel safe/ in control not tied to specific experience

Repetitive

Behavior

Avoidance

Uncertainty, bad things happening in the future, feeling not right

Task Completion Doing it "perfect"

Resolving/fixing/evening out

Relationship to

Thoughts

Underlying

Feature

\section{PTSD}

Focused on a memories of specific past event, replaying/flashbacks

Past memories of trauma; triggers; painful emotions associated with the traumatic event

Doing it "right" to maintain safety/control, escaping danger

Must be controlled, neutralized, figured out, prevented from coming To be avoided

true

Preventing possible feared consequences; intolerance of uncertainty Avoiding emotional pain \& re-experiencing trauma

Adapted from Van Kirk, N. (2015, August). When fears become real: Post-traumatic OCD. In Van Kirk, N. (Chair), Solodyna, A., Grayson, J. \& Timpano, K. Understanding the Impact of Comorbid PTSD on the Conceptualization and Treatment of OCD. Symposium presented at the 22nd annual International Obsessive Compulsive Disorder Foundation conference, Boston, MA

b. Thinking back, did your OCD symptoms start before or after your traumatic experiences? (If concurrently, select "after")
i. Before
ii. After
iii. Simultaneous

1. If before, did you notice an increase in your symptoms following trauma?

c. Do you believe your OCD and trauma are linked in any way?
i. $\quad$ Yes
ii. $\quad$ No
1. If Yes, how do you think they are linked? (Long answer)

d. Do you think that the presence of [OCD or PTSD] made you more vulnerable to developing [OCD or PTSD]?
i. $\quad$ Yes
ii. No
1. If Yes, can you please describe that for me?

**Participant will go on to Part B if they have OCD, at least one event they considered Traumatic, and some overlap of their OCD and trauma symptoms**. 


\section{PART B}

1. Administer LEC (via screen share) https://www.ptsd.va. gov/professional/assessment/documents/LEC5_ Standard_Self-report.PDF

2. As mentioned above, I am interested in learning about whether your OCD obsessions and rituals overlap with/ relate to your traumatic experiences you described above. You indicated that you experienced [Trauma from LEC]. What obsessions/rituals do you have that relate to this experience?

\begin{tabular}{|l|l|l|l|}
\hline $\begin{array}{l}\text { Obsessions/Thoughts that } \\
\text { overlap between } \\
\text { PTSD/OCD }\end{array}$ & $\begin{array}{l}\text { Rituals or } \\
\text { Avoidance Behavior }\end{array}$ & $\begin{array}{l}\text { Which more accurately } \\
\text { describes the feeling you } \\
\text { achieve by completing the } \\
\text { ritual? } \\
\text { a. A greater sense of safety } \\
\text { b. A greater sense of } \\
\text { certainty around future } \\
\text { outcomes }\end{array}$ & $\begin{array}{l}\text { If you resist the [Identified } \\
\text { Ritual/Behavior] do you } \\
\text { experience intrusive } \\
\text { thoughts or images of: } \\
\text { a. Past stressful events } \\
\text { b. Potential future } \\
\text { scenarios (e.g. "what if" } \\
\text { scenarios)? }\end{array}$ \\
\hline & & & \\
\hline
\end{tabular}

3. What percentage do you think your OCD and Trauma symptoms overlap, content wise? For example, if your trauma was a house fire, do you obsess about your stove being on and check it frequently as a ritual?

a. $\%$ (indicate $\%$ that trauma and rituals/obsessions overlap)

4. If your $\mathrm{OCD}$ disappeared tomorrow, how do you think that would shift your experience of your trauma symptoms? (long answer)

5. Do you feel your OCD behaviors serve as a coping mechanism for your trauma related memories/thoughts/experiences
a. Yes
b. No
i. Please describe (long answer)

6. Following the identified traumatic event, did you develop any feelings of "mental contamination" or an internal feeling of being unclean, dirty, or contaminated in some way, despite not being actually physically dirty?

a. Yes

i. If Yes: Do you believe this feeling

1. stems directly from your traumatic experience (i.e. is related to your PTSD symptoms)

2. is is associated with OCD fears/obsessional themes

3. _ is both connected to the trauma experience and your OCD symptoms

b. No

Did you find your onset of OCD symptoms traumatic?

c. Yes

i. Please describe (long answer)

d. No 
1. Considering each of these aspects of your identity...

a. Do any overlap with your

i. OCD Symptoms?

1. $\quad$ No

a. Please Describe

ii. PTSD Symptoms?

1. No

2. Y Yes

a. Please Describe

iii. Both?

1. No

2. Yes

a. Please Describe

b. Do any inform the development of your symptoms? (long answer)

c. Do any inform the maintenance of your symptoms? (long answer)

Data Availability Data sharing not applicable to this article as no datasets were generated or analyzed during the current study.

\section{Declarations}

Conflict of Interest The authors have no relevant financial or nonfinancial interests to disclose.

Ethics Approval This is an observational study. There are no case studies or data used.

Consent There are no case studies or data used.

\section{References}

Abramowitz, J. S., Deacon, B. J., Olatunji, B. O., Wheaton, M. G., Berman, N. C., Losardo, D., Timpano, K. R., McGrath, P. B., Riemann, B. C., Adams, T., Björgvinsson, T., Storch, E. A., \& Hale, L. R. (2010). Assessment of obsessive-compulsive symptom dimensions: Development and evaluation of the dimensional obsessive-compulsive scale. Psychological Assessment, 22(1), 180-198. https://doi.org/10.1037/a0018260.

Badour, C. L., Bown, S., Adams, T. G., Bunaciu, L., \& Feldner, M. T. (2012). Specificity of fear and disgust experienced during traumatic interpersonal victimization in predicting posttraumatic stress and contamination-based obsessive-compulsive symptoms. Journal of Anxiety Disorders, 26(5), 590-598. https://doi.org/10.1016/j. janxdis.2012.03.001.

Blevins, C. A., Weathers, F. W., Davis, M. T., Witte, T. K., \& Domino, J. L. (2015). The posttraumatic stress disorder checklist for DSM-5 (PCL-5): Development and initial psychometric evaluation. Journal of Traumatic Stress, 28, 489-498. https://doi.org/10.1002/ jts. 22059 .
Blankenship, D. M. (2017). Five efficacious treatments for posttraumatic stress disorder: An empirical review. Journal of mental health counseling, 39(4), 275-288. https://doi.org/10.17744/mehc.39.4.01.

Brown, T. A., Campbell, L. A., Lehman, C. L., Grisham, J. R., \& Mancill, R. B. (2001). Current and lifetime comorbidity of the DSM-IV anxiety and mood disorders in a large clinical sample. Journal of Abnormal Psychology, 110(4), 585-599. https://doi.org/10.1037// 0021-843X.110.4.58.

Courtois, C. A. (2004). Complex trauma, complex reactions: Assessment and treatment. Psychotherapy: Theory, research, practice, training, 41(4), 412.

Craske, M. G., Treanor, M., Conway, C. C., Zbozinek, T., \& Vervliet, B. (2014). Maximizing exposure therapy: An inhibitory learning approach. Behaviour Research and Therapy, 58, 10-23. https://doi. org/10.1016/j.brat.2014.04.006.

Cromer, K. R., Schmidt, N. B., \& Murphy, D. L. (2007). An investigation of traumatic life events and obsessive-compulsive disorder. Behaviour Research and Therapy, 45, 1683-1691. https://doi.org/ 10.1016/j.brat.2006.08.018.

Dykshoorn, K. L. (2014). Trauma-related obsessive-compulsive disorder: A review. Health Psychology and Behavioral Medicine, 2(1), 517-528. https://doi.org/10.1080/21642850.2014.905207.

Eddy, K. T., Dutra, L., Bradley, R., \& Westen, D. (2004). A multidimensional meta-analysis of psychotherapy and pharmacotherapy for obsessive-compulsive disorder. Clinical Psychology Review, 24(8), 1011-1030. https://doi.org/10.1016/j.cpr.2004.08.004.

Elliott, C. M., \& Radomsky, A. S. (2013). Meaning and mental contamination: Focus on appraisals. Clinical Psychologist, 17, 17-25. https://doi.org/10.1111/cp.12002.

Fairbrother, N., Newth, S. J., \& Rachman, S. (2005). Mental pollution: feelings of dirtiness without physical contact. Behaviour Research and Therapy, 43(1), 121-130. https://doi.org/10.1016/j.brat.2003. 12.005

First, M. B., Williams, J. B. W., Karg, R. S., \& Spitzer, R. L. (2015). Structured Clinical Interview for DSM-5-Disorders, Clinical Trials Version (SCID-5-CT). Arlington, VA, American Psychiatric Association. 
Fletcher, T. L., Van Kirk, N., \& Hundt, N. (2020). Obsessive-compulsive disorder and comorbid posttraumatic stress disorder. In advanced casebook of obsessive-compulsive and related disorders (pp. 105121). Academic press.

Foa, E. B., Hembree, E. A., \& Rothbaum, B. O. (2019). Prolonged exposure therapy for PTSD: Emotional processing of traumatic experiences, therapist guide (2nd ed.). Oxford University Press.

Foa, E. B., Yadin, E., \& Lichner, T. K. (2012). Exposure and response (ritual) prevention for obsessive compulsive disorder: Therapist guide. Oxford University Press.

Fontenelle, L. F., Cocchi, L., Harrison, B. J., Shavitt, R. G., Rosário, M. C. D., Ferrão, Y. A., et al. (2012). Towards a post-traumatic subtype of obsessive-compulsive disorder. Journal of Anxiety Disorders, 26(2), 377-383. https://doi.org/10.1016/j.janxdis.2011.12.001.

Gershuny, B. S., Baer, L., Jenike, M. A., Minichiello, W. E., \& Wilhelm, S. (2002). Comorbid posttraumatic stress disorder: Impact on treatment outcome for obsessive-compulsive disorder. American Journal of Psychiatry, 159(5), 852-854. https://doi.org/10.1176/ appi.ajp.159.5.852.

Gershuny, B. S., Baer, L., Radomsky, A. S., Wilson, K. A., \& Jenike, M. A. (2003). Connections among symptoms of obsessive-compulsive disorder and posttraumatic stress disorder: A case series. Behaviour Research and Therapy, 41(9), 1029-1041. https://doi.org/10.1016/ S0005-7967(02)00178-X.

Gershuny, B. S., Baer, L., Parker, H., Gentes, E. L., Infield, A. L., \& Jenike, M. A. (2008). Trauma and posttraumatic stress disorder in treatment-resistant obsessive-compulsive disorder. Depression and Anxiety, 25(1), 69-71. https://doi.org/10.1002/da.20284.

Goodman, W. K. (1989a). The Yale-brown obsessive compulsive scale: I. development, use, and reliability. Archives of general psychiatry, 46, 1006-1011. https://doi.org/10.1001/archpsyc.1989. 01810110048007.

Goodman, W. K. (1989b). The Yale-brown obsessive compulsive scale: Ii. Validity. Archives of general psychiatry, . https://doi.org/10. 1001/archpsyc.1989.01810110054008, 46, 1012, 1016.

Gray, M. J., Litz, B. T., Hsu, J. L., \& Lombardo, T. W. (2004). Psychometric properties of the life events checklist. Assessment, 11(4), 330-341.

Grayson, J. B. (2010). OCD and intolerance of uncertainty: Treatment issues. Journal of Cognitive Psychotherapy, 24(1), 3-15. https://doi. org/10.1891/0889-8391.24.1.3.

Herman, J. L. (1992). Complex PTSD: A syndrome in survivors of prolonged and repeated trauma. Journal of Traumatic Stress, 5(3), 377-391.

Nacasch, N., Fostick, L., \& Zohar, J. (2011). High prevalence of obsessive-compulsive disorder among posttraumatic stress disorder patients. European Neuropsychopharmacology, 21, 876-879. https://doi.org/10.1016/j.euroneuro.2011.03.007.

Ojserkis, R., Boisseau, C. L., Reddy, M. K., Mancebo, M. C., Eisen, J. L., \& Rasmussen, S. A. (2017). The impact of lifetime PTSD on the seven-year course and clinical characteristics of OCD. Psychiatry Research, 258, 78-82. https://doi.org/10.1016/j.psychres.2017.09. 042.

Pinciotti, C. M., Riemann, B. C., \& Wetterneck, C. T. (2020). Differences in intolerance of uncertainty in OCD and comorbid PTSD underlying attenuated treatment response. Annals of Psychiatry and Mental Health, 8(1), 1142.

Rachman, S. (1991). A psychological approach to the study of comorbidity. Clinical Psychology Review, 11(4), 461-464.

Rachman, S. (1994). Pollution of the mind. Behaviour Research and Therapy, 32, 311-314.

Rachman, S., Radomsky, A. S., Elliott, C. M., \& Zysk, E. (2012). Mental contamination: The perpetrator effect. Journal of Behavior Therapy and Experimental Psychiatry, 43, 587-593. https://doi.org/10.1016/ j.jbtep.2011.08.002.

Radomsky, A. S., Shafran, R., Coughtrey, A. E., \& Rachman, S. (2010). Cognitive-behavior therapy for compulsive checking in OCD. Cognitive and Behavioral Practice, 17(2), 119-131.

Resick, P. A., Monson, C. M., \& Chard, K. M. (2016). Cognitive processing therapy for PTSD: A comprehensive manual. Guilford Publications.

Riggs, D. S. (2000). Treatment of concurrent PTSD and OCD: A commentary on the case of Howard. Cognitive and Behavioral Practice, 7(1), 130-132. https://doi.org/10.1016/S1077-7229(00)80015-2.

Ruscio, A. M., Stein, D. J., Chiu, W. T., \& Kessler, R. C. (2010). The epidemiology of obsessive-compulsive disorder in the National Comorbidity Survey Replication. Molecular Psychiatry, 15(1), 53-63. https://doi.org/10.1038/mp.2008.94.

Salkovskis, P. M. (1985) Obsessional-compulsive problems: A cognitivebehavioural analysis. Behaviour Research and Therapy 23(5), 571583. https://doi.org/10.1016/0005-7967(85)90105-6.

Shavitt, R. G., Valério, C., Fossaluza, V., da Silva, E. M., Cordeiro, Q., Diniz, J. B., ... \& Miguel, E. C. (2010). The impact of trauma and post-traumatic stress disorder on the treatment response of patients with obsessive-compulsive disorder. European archives of psychiatry and clinical neuroscience,260 (2), 91-99.

Sheehan, D. V., Lecrubier, Y., Sheehan, K. H., Amorim, P., Janavs, J., Weiller, E., et al. (1998). The MINI-international neuropsychiatric interview (MINI): The development and validation of a structured diagnostic psychiatric interview for DSM-IV and ICD-10. Journal of Clinical Psychiatry, 59(20), 22-33.

Tolin, D. F., Gilliam, C., Wootton, B. M., Bowe, W., Bragdon, L. B., Davis, E., Hannan, S. E., Steinman, S. A., Worden, B., \& Hallion, L. S. (2018). Psychometric properties of a structured diagnostic interview for DSM-5 anxiety, mood, and obsessive-compulsive and related disorders. Assessment, 25(1), 3-13.

Van der Kolk, B. A. (2005). Developmental trauma disorder. A new, rational diagnosis for children with complex trauma histories. Psychiatric annals, 35(5), 401408.

Van Kirk, N., Fletcher, T. L., Wanner, J. L., Hundt, N., \& Teng, E. J. (2018). Implications of comorbid OCD on PTSD treatment: A case study. Bulletin of the Menninger Clinic, 82(4), 344-359.

Wilhelm, S., \& Steketee, G. S. (2006). Cognitive therapy for obsessive compulsive disorder: A guide for professionals. New Harbinger Publications.

Publisher's Note Springer Nature remains neutral with regard to jurisdictional claims in published maps and institutional affiliations. 